\title{
Кварцевые и железо-глиноземистые метасоматиты в ассоциации с кислыми вулканитами - комагматами гранитов рапакиви: геохимия, возраст и структурное положение (Внешние Острова Финского залива)
}

\author{
Терехов Е.Н. ${ }^{1}$, Макеев А.Б. ${ }^{2}$, Баянова Т.Б. ${ }^{3}$, Щербакова Т.Ф. ${ }^{1}$, Лютоев В.П. ${ }^{4}$, Серов П.А. ${ }^{3}$ \\ ${ }^{1}$ Геологический институт PAH, Москва, terekhoff.zhenya@yandex.ru \\ ${ }^{2}$ Институт геологии рудных месторождений, петрографии, минералогии и геохимии, Москва, \\ abmakeev@mail.ru \\ ${ }^{3}$ Геологический институт КНЦ РАН, Anamuты, bayanova@geoksc.apatity.ru \\ ${ }^{4}$ Институт геологии Коми НЦ УрО РАН, Сыктыєккар
}

Аннотация. В Финском заливе, в центральной части Балтийско-Мезенской тектонической зоны на острове Большой Тютерс детально изучено проявление вторичных кварцитов и метасоматитов силлиманитмагнетит-каолинитового состава. Вторичные кварциты образовались по свекофеннским гнейсам (2.00-1.85 млрд. лет) и прорваны дайками гранитного состава с возрастом (1.65-1.50 млрд. лет), что определяет их раннерифейский возраст. Ведущая роль в формировании вторичных кварцитов придаётся экзгаляционной деятельности вулканов, продукты которых, в виде лавовых покровов, сохранились на о. Гогланд. Вулканиты с возрастом 1.65 млрд. лет, являются комагматами гранитов рапакиви, а их эффузивное проявление среди интрузивных массивов обусловлено положением магматического очага в региональной сдвиговой зоне. Гранитные жилы, секущие кварциты, имеют возраст 1.65-1.50 млрд. лет, что согласуется с геохронологическими данными о длительном (100 млн. лет) периоде формирования гранитов рапакиви в южном обрамлении Балтийского щита.

Ключевые слова: вторичные кварциты, метасоматиты, кислые вулканиты, Балтийский щит, граниты рапакиви, сдвиговая зона.

\section{Quartz and iron-alumina metasomatites in association with acid volcanites - comagmates of rapakivi granites: geochemistry, age and structural position (Outer Islands of the Gulf of Finland)}

\author{
Terekhov E.N. ${ }^{1}$, Makeev A.B. ${ }^{2}$, Bayanova T.B. ${ }^{3}$, Shcherbakova T.F. ${ }^{1}$, Lyutoev V.P. ${ }^{4}$, Serov P.A. ${ }^{3}$ \\ ${ }^{1}$ Geological Institute of RAS, Moscow, terekhoff.zhenya@yandex.ru \\ ${ }^{2}$ Institute of Geology of ore deposits, petrography, Mineralogy and Geochemistry, Moscow, \\ abmakeev@mail.ru \\ ${ }^{3}$ Geological Institute, Kola Science Centre, Russian Academy of Sciences, Apatity, bayanova@geoksc.apatity.ru \\ ${ }^{4}$ Institute of Geology Komi SC UB RAS, Syktyvkar
}

\begin{abstract}
The manifestation of secondary quartzites and metasomatites of sillimanite-magnetite-kaolinite composition has been studied in detail in the Gulf of Finland, in the Central part of the Baltic-Mezen tectonic zone on the island of Greater Tyuters. Secondary quartzite formed svecofennian gneiss (of 2.00-1.85 Ga) and broken dykes of granitic composition with age $(1.65-1.50 \mathrm{Ga})$, which determines their early riphey age. The leading role in the formation of secondary quartzites is given to the exhalation activity of volcanoes, the products of which, in the form of lava covers, have been preserved on Gogland island. Volcanites with an age of $1.65 \mathrm{Ga}$, are comagmates of rapakivi granites, and their effusive manifestation among intrusive massifs is due to the position of the magmatic camera in the regional shear zone. Granite veins, break of secondary quartzites, have an age of 1.65-1.50 Ga, which is consistent with geochronological data on the long (100 million years) period of formation of rapakivi granites in the southern frame of the Baltic shield.
\end{abstract}

Key words: secondary quartzites, metasomatites, acid volcanites, Baltic shield, rapakivi granites, shear zone.

Впервые для восточной части Балтийского щита выявлено и детально изучено крупное проявление кондиционного кварца на острове Большой Тютерс в архипелаге Внешних Островов Финского залива (рис. 1). Исследования показали, что эти существенно кварцевые породы являются вто- 


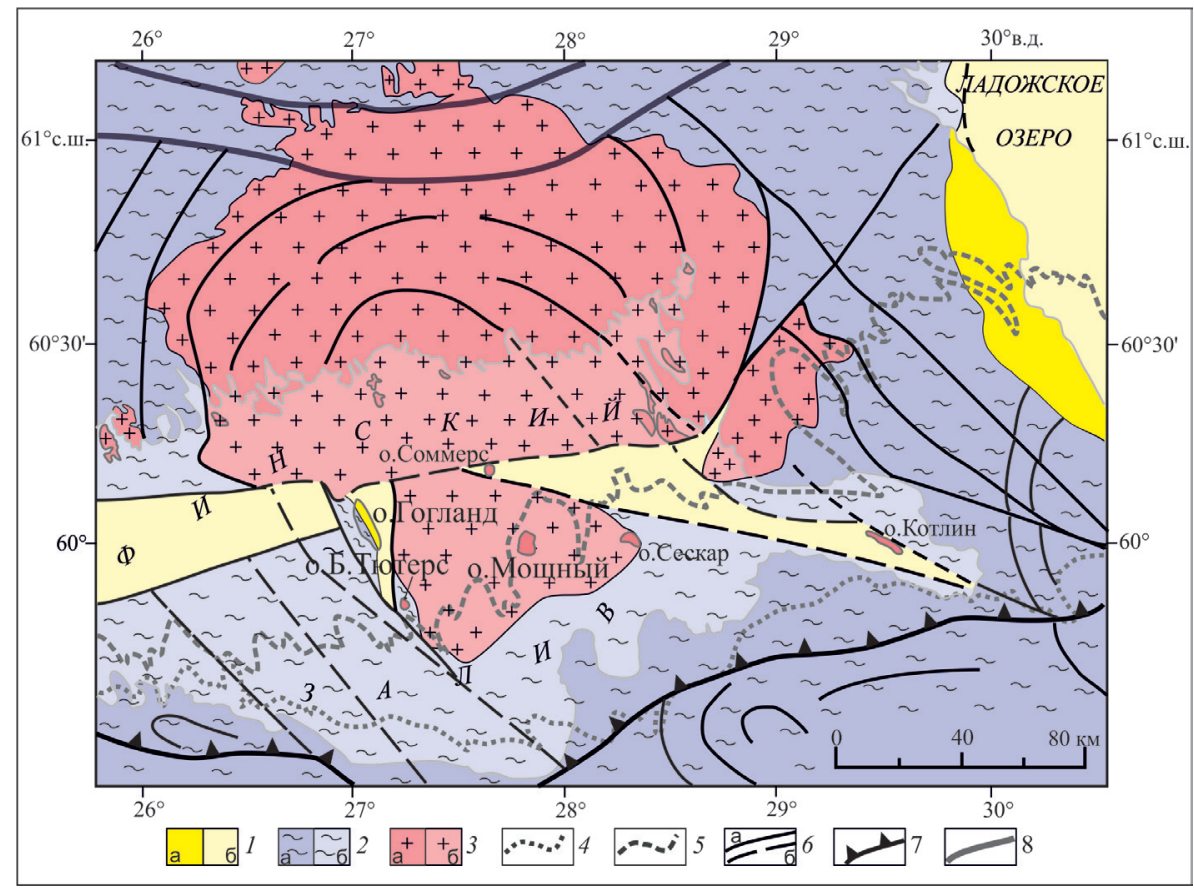

Рис. 1. Структурно-геологическая схема восточной части Финского залива.

1 - рифейские отложения (1.65-1.10 млрд. лет): на суше (а), в акватории (б); 2 - свекофеннские отложения (2.00-1.85 млрд. лет): на суше (а), в акватории (б); 3 - граниты рапакиви (1.65-1.60 млрд. лет): на суше (а), в акватории (б); 4 - подошва палеозойских отложений; 5 - подошва вендских отложений; 6 - разломы: достоверные (а) и предполагаемые (б); 7 - Балтийско-Ладожский глинт (уступ); 8 - северное ограничение БалтийскоМезенской тектонической зоны.

Fig. 1. Structural-geological scheme of the Eastern part of the Gulf of Finland.

1 - Riphean sediments (1.65-1.10 Ga): on land (a), in the water area (b); 2 - Svecofennian sediments (2.00-1.85 Ga): on land (a), in the water area (b); 3 - rapakivi granites (1.65-1.60 Ga): on land (a), in the water area (b); 4 - the sole of Paleozoic sediments; 5 - the bottom of Vendian sediments; 6 - faults: reliable (a) and assumed (b); 7 - Baltic-Ladoga glint; 8 - Northern limitation of the Baltic-Mezen tectonic zone.

ричными кварцитами, которые по аналогии с классическими проявлениями подобных образований в Казахстане, по нашему мнению также образовались под влиянием флюидов, сопровождающих кислый вулканизм (Терехов и др., 2017). Вторичные кварциты, образующиеся в процессах кислотного выщелачивания в областях активного вулканизма, являются важным источником высококачественного кварцевого сырья, как одного из основных компонентов минеральной базы высокотехнологичного производства. В отличие от окварцованных пород амфиболитовой и гранулитовой фаций, достаточно широко развитых на территории Балтийского щита, изученные вторичные кварциты являются низкотемпературными образованиями, кристаллизовавшимися в условиях зеленосланцевой фации. Благодаря этому алюминий из породообразующих минералов сланцев - пород протолитов (слюд и полевого шпата) - почти полностью перешёл во вторичные минералы (слюды, каолинит, гематит), не загрязняя кристаллическую решетку кварца (Лютоев и др., 2017).

Изучение вторичных кварцитов о. Б.Тютерс повлекло за собой необходимость исследования и других, ассоциирующих с ними образований и их особенностей, рассматриваемых в данной работе: 1 - своеобразные, не найденные нами в литературе железо-магнезиальные метасоматиты с силлиманитом и каолинитом с зональными кристаллами магнетита; 2 - кислые вулканиты, предположительно комагматы гранитам рапакиви с образованием которых связано формирование вторичных кварцитов; 3 - дайки гранитного состава, спорного формационного типа, секущие вторичные кварциты и тем самым определяющие верхнюю возрастную границу их формирования; 4 - выявление геотектонических причин появления этих редких геологических объектов, не характерных для Балтийского щита. 
Большая часть коренных пород о. Б. Тютерс представлена массивными, не полосчатыми кварцитами. Они имеют различную окраску от бесцветной к серой и бурой с постепенными переходами. Обычно это крупнозернистые, массивные, часто «сливные», но местами пористые разности, которые секутся многочисленными вертикальными и реже наклонными жилами, также кварцевого состава, мощностью 10-20 см. В кварцитах, на старом сколе, часто видны теневые структуры в виде разноцветной полосчатости, иногда типа мигматитовой с характерными складками. На свежем сколе никаких различий не видно и все породы представлены кварцитами, которые в основной массе и в кварцевых жилах одинаковы по составу, хотя в поле (в обнажениях) последние кажутся более светлыми и сливными. В целом кварциты не образуют пластов, складок, не выявлено осадочной полосчатости. Они занимают всю обнаженную часть острова и развиты как у уреза воды, так и в водораздельной части острова, при этом вертикальной и горизонтальной зональности не отмечено. Среди кварцитов выделяются линейные зоны трещиноватости, наложенные на кварциты, центральные части которых часто сложены массивными железо-глиноземистыми метасоматитами, имеющими ярко бурую окраску. Мощность этих зон до первых метров и прослежены они на сотни метров. Они сложены силлиманит-магнетит-каолинитовыми породам. Метасоматиты обогащены $\mathrm{Al}_{2} \mathrm{O}_{3}$ (16-23 мас. \%), в отличие от (2-5 мас. \%) в - кварцитах. В метасоматитах преобладает окисное железо, в кварцитах - закисное. Метасоматиты практически не содержат ни щелочных, ни щелочноземельных элементов. Они обогащены $\operatorname{Zr}$ (146-199 г/т) и рядом других элементов-примесей, в том числе РЗЭ (рис. 2 a). Причем для обоих типов пород характерна незначительная и близкая степень фракционирования $\left((\mathrm{La} / \mathrm{Yb})_{\mathrm{n}}=6.55\right.$ и 6.17). Метасоматиты по набору минералов не отличаются от кварцитов, но различаются их количественными соотношениями и составом. Особый интерес представляет в метасоматитах магнетит. Он содержит множество кварцевых включений с каолини-
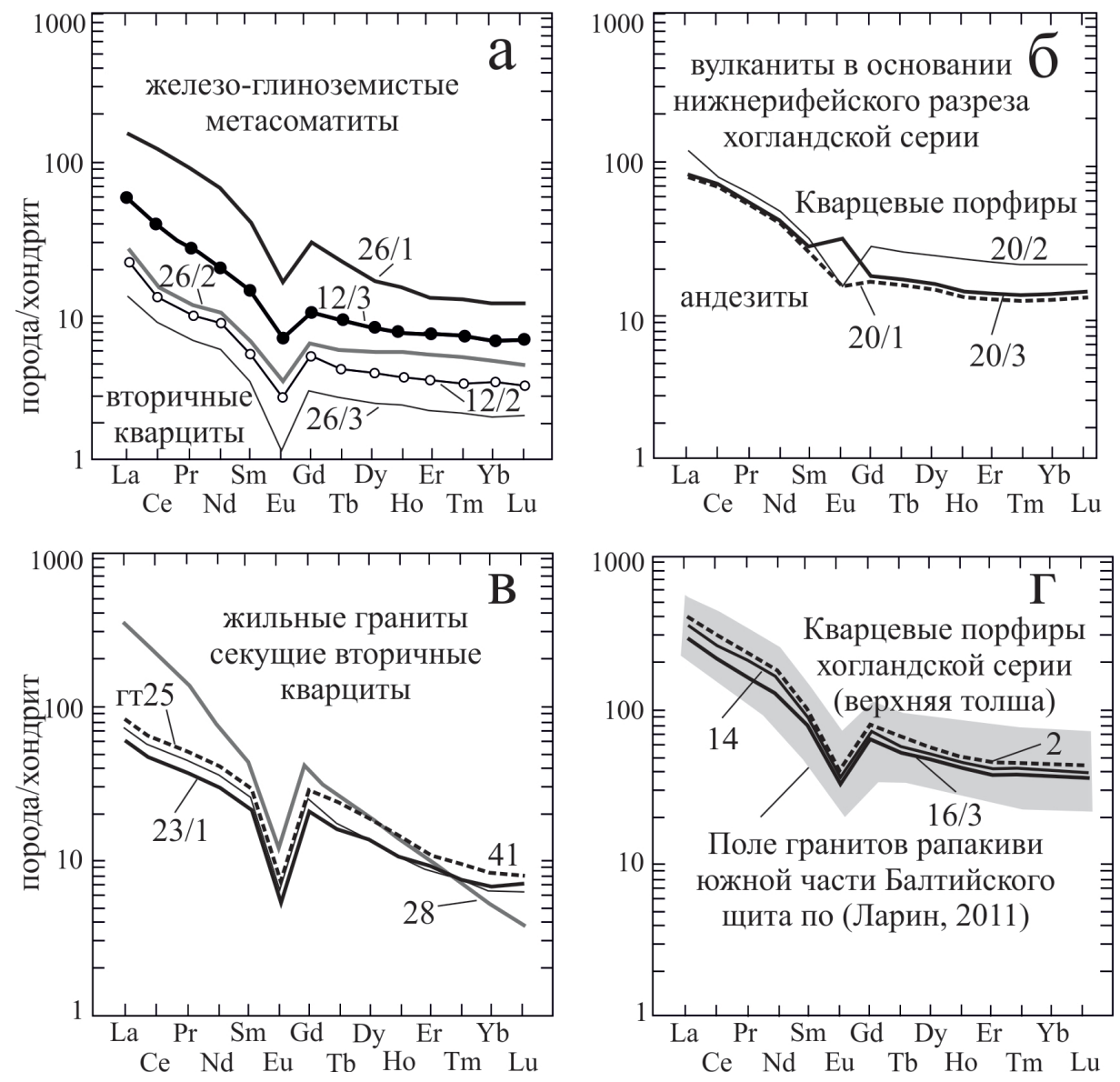

Рис. 2. График распределения РЗЭ в раннерифейских породах островов Большой Тютерс (a, в) и Гогланд (б, г).

Fig. 2. The plot of REE distribution in the early Riphean rocks of the Great Tyuters (a, B) and Gogland $(\sigma, \Gamma)$ Islands. 


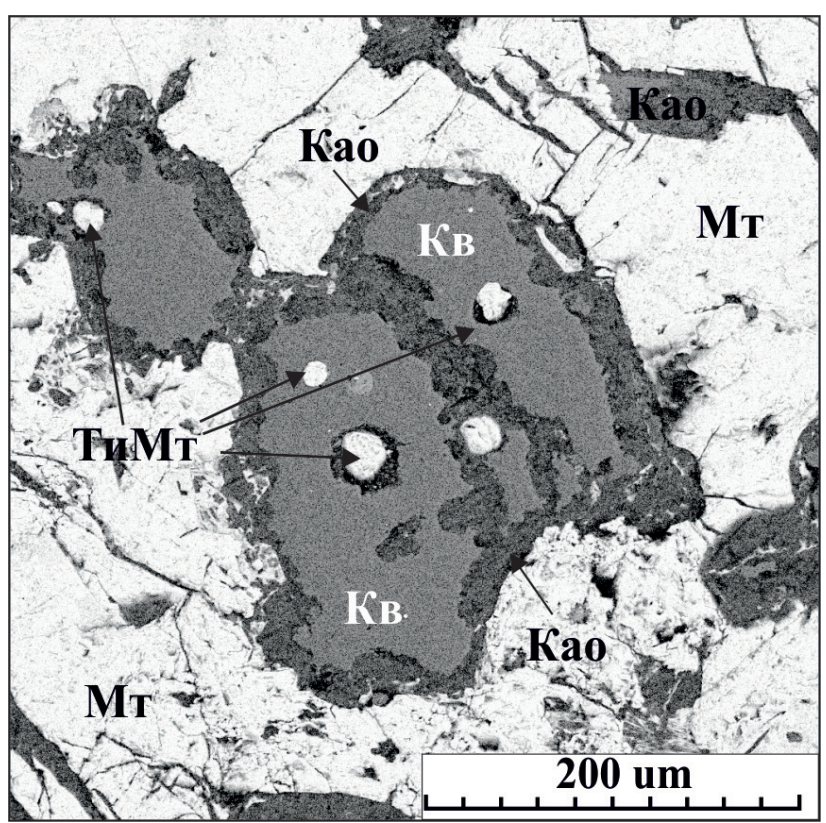

Рис. 3. Микрофотография внутреннего строения зерна магнетита в железо-глиноземистых метасоматитах. Као - каолинит, Кв - кварц, Мт - магнетит, ТиМт - титаномагнетит (сделана на микрозонде).

Fig. 3. Micropfoto of the internal structure of the magnetite grain in iron-alumina metasomatites). Kao-kaolinite, Кв-quartz, Мт-magnetite, ТиМт-titanomagnetite (microprobe image). положен остров Гогланд, большая часть которого сложена кислыми вулканитами, имеющие возраст 1.65 млрд. лет, которые рассматриваются как комагматы гранитов рапакиви (Беляев, 2013). Именно с вулканизмом этого периода можно связать формирование вторичных кварцитов. Сами вулканиты, несмотря на близость возрастов с гранитами рапакиви, заметно отличаются от них по некоторым характеристикам, вероятно, это связано с различным тектоническим положением этих комплексов, что и определяет состав конечных продуктов магматической деятельности.

Важное значение для понимания возраста вторичных кварцитов имеют дайки кислого состава, которые их прорывают и содержат ксенолиты, представленные самими кварцитами. По составу и ориентировке в пределах острова Б.Тютерс выделены два типа даек. Первый тип - это дайки субширотного простирания, то есть параллельные Балтийско-Мезенской тектонической зоне (флексуры Полканова). Их мощность от 50 см до 20 м. В мелких дайках отчетливо видна флюидальность параллельная контактам, что указывает на выжимание расплава вдоль направления развития будущей дайки. Ксенолиты кварцитов также вытянуты по простиранию этих даек. Дайки второго типа сложены массивными гигантозернистыми гранитами, мощностью от 1 до 15 м. Они имеют субмеридиональное простирание и характерный состав типичный для гранитных пегматитов (высокие $(\mathrm{La} / \mathrm{Yb})_{n}$ отношения $=100$ (рис. 2 в, проба 28). В одной из даек встречен крупный ксенолит не окварцованных пород - сланцев с горизонтом амфиболитов и редкими жилками неосомы. Подобные породы весьма близки по облику и составу к супракрустальным образованиям свекофеннского комплекса, развитых вдоль западного берега о. Гогланда. В лаборатории изотопной геохимии и геохронологии ИГЕМ РАН проведены определения К-Ar возраста гранитных даек. С некоторой долей условности можно говорить, что дайки широтного направления более древние, чем меридиональные $(1680 \pm 30$ и $1660 \pm 30$ млн. лет, соответственно), то есть по возрасту они близки гранитам рапакиви Выборгского массива, для которых характерны датировки около 1650 млн. лет (Ларин, 2011). Очевидно, что гранитные дайки рвут уже сформировавшиеся вторичные кварциты. 
Комплексные изотопные исследования гранитов и вторичных кварцитов проводились и в Геологическом институте Кольского НЦ РАН. Для единичных зерен циркона из гранита меридиональной дайки получен более молодой конкордантый возраст (1560 10 млн. лет), который соответствует возрасту формирования уже другого массива гранитов рапакиви - Салминского. Таким образом, можно утверждать, что формирование вторичных кварцитов предшествовало образованию массивов рапакиви южной части Балтийского щита. Исследования также показали, что изотопная $\mathrm{Sm}-\mathrm{Nd}$ система гранитов из даек о. Б.Тютерс была нарушена, вероятно, под воздействием флюидов и метасоматических процессов. Процессы эксгаляционной деятельности, тектонической активности, метасоматической или флюидной переработки, развитие многочисленных зон трещиноватости, по-видимому, обеспечили условия для нарушения изотопной Sm-Nd системы на уровне пород в целом. Это привело к тому, что были получены значения $\varepsilon \mathrm{Nd}(\mathrm{T})$ до +8.0, a $\mathrm{Sm}-\mathrm{Nd}$ модельные возрасты варьируют от архейского до мезопротерозойского. Двухточечные «изохроны» по породе и ильмениту во вторичных кварцитах дают сильно омоложенные возрасты (около 1.0 млрд. лет и 460 млн. лет), возможно связанные с поздними эпизодами флюидно-метасоматической переработки, которые совпадают с периодами тектонической активизации краевой части Балтийского щита.

Таким образом, гранитные жилы, секущие вторичные кварциты, имеют возраст 1.65-1.50 млрд. лет, что указывает на раннерифейский возраст проявлений кислого вулканизма в этом районе, следы которого сохранились на о. Гогланд, и под влиянием которого образовались вторичные кварциты. При этом современная гряда островов Гогланд - Б. Тютерс является поперечной структурой Финского залива, так же как и рассматриваемая раннерифейская структура, вероятно, являлась поперечной по отношению к главному простиранию тектонической зоны южного обрамления Балтийского щита, известной как Балтийско-Мезенская или флексура Полканова.

Работа выполнена в рамках программы фундаментальных исследований ГИН РАН, при частичной финансовой поддержке гранта РФФИ № 18-05-00485 и Программы Президиума РАН № 19. Часть исследований проводилась в рамках темы НИР ГИ КНЦ РАН № 0226-2019-0053.

\section{Литература}

1. Беляев А.М. Петрология вулканических пород формации рапакиви (о. Гогланд) // Региональная геология и металлогения. 2013. № 55. С. 28-36.

2. Ларин А.М. Граниты рапакиви и ассоциирующие породы. СПб. Изд-во: Наука. 2011. 402 с.

3. Лютоев В.П., Терехов Е.Н., Макеев А.Б., Лысюк А.Ю., Головатая О.С. Кварц острова Большой Тютерс: спектроскопические исследования // Минералогия техногенеза. 2017. Т. 18. С. 88-108.

4. Наковник Н.И. Вторичные кварциты СССР и связанные с ними месторождения полезных ископаемых. Изд-во: Недра. 1968. 335 с.

5. Терехов Е.Н., Макеев А.Б., Прокофьев В.Ю., и др. Природа вторичных кварцитов острова Большой Тютерс (Финский залив, Россия) // Литосфера. 2017. Т. 17. № 6. С. 62-80.

6. Laitakari I., Ramo T., Suominen V., Stepanov K. and Amantov A. Subjotnian: rapakivi granites and related rocks of the gulf of Finland // Geol. Survey of Finland, special Paper. 1996. 21. P. 59-97. 